\title{
P2X7 Receptor Function in Bone-Related Cancer
}

\author{
Elena Adinolfi, Francesca Amoroso, and Anna Lisa Giuliani \\ Department of Experimental and Diagnostic Medicine, Section of General Pathology, University of Ferrara, \\ Via Borsari 46, 44121 Ferrara, Italy \\ Correspondence should be addressed to Elena Adinolfi, elena.adinolfi@unife.it
}

Received 14 May 2012; Revised 23 July 2012; Accepted 25 July 2012

Academic Editor: Isabel Orriss

Copyright () 2012 Elena Adinolfi et al. This is an open access article distributed under the Creative Commons Attribution License, which permits unrestricted use, distribution, and reproduction in any medium, provided the original work is properly cited.

\begin{abstract}
Modulation of tumor microenvironment by different mediators is central in determining neoplastic formation and progression. Among these molecules extracellular ATP is emerging as a good candidate in promoting cell growth, neovascularization, tumorhost interactions, and metastatization. This paper summarizes recent findings on expression and function of P2X7 receptor for extracellular ATP in primary and metastatic bone cancers. Search of mRNA expression microchip databases and literature analysis demonstrate a high expression of P2X7 in primary bone tumors as well as in other malignancies such as multiple myeloma, neuroblastoma, breast, and prostate cancer. Evidence that P2X7 triggers NFATc1, PI3K/Akt, ROCK, and VEGF pathways in osteoblasts promoting either primary tumor development or osteoblastic lesions is also reported. Moreover, P2X7 receptor is involved in osteoclast differentiation, RANKL expression, matrix metalloproteases and cathepsin secretion thus promoting bone resorption and osteolytic lesions. Taken together these data point to a pivotal role for the P2X7 receptor in bone cancer biology.
\end{abstract}

\section{Introduction}

Primary bone cancers, malignancies that originate directly from bone cells, are quite rare diseases. According to USA National Cancer Institute about 2810 people were diagnosed, and 1500 died of bone and joint cancer in 2011. A similar incidence, one affected individual every 100.000, was reported in the same year by the Italian Association for Cancer Research (AIRC). Primary bone cancers generally originate in long bones of limbs and affect children or young adults accounting for $6 \%$ of all new pediatric cancer per year [1]. Among primary bone cancers osteosarcoma is the most frequent [2]. Two different osteosarcoma variants are known: a conventional high-grade form intramedullary located at the metaphysis of long tubular bones, frequent in adolescents, and a rarer low-grade variant arising at the surface of long bones, showing a better prognosis, more frequent among adults than young people. Frequency of lowgrade is 20 times lower than high-grade ones [3].

A peculiar primary tumor, causing bone damage without need of spreading from the original site, is multiple myeloma. Multiple myeloma is a clonal B-cell malignancy characterized by an accumulation of mature plasma cells in the bone marrow, leading to bone destruction and failure of normal hematopoiesis $[4,5]$. The incidence is 3-9 cases/100.000/year; it is more frequent among elderly with a slight male prevalence. Multiple myeloma remains an incurable disease even with the use of proteasome inhibitor bortezomib, immuno-modulatory drugs (thalidomide or lenalidomide), and high-dose chemotherapy associated to autologous stem cell transplantation, as part of first-line therapy [6]. In multiple myeloma, tumor and stromal cells interact via adhesion molecules and cytokine networks to simultaneously promote tumor cell survival, drug resistance, angiogenesis, and disordered bone metabolism.

Bone metastasis of extra-bone high-grade solid tumors is more frequent than primary bone cancers. The rate of bone metastasis is about $70 \%$ in breast, melanoma, lung and prostate cancer and about $15-30 \%$ in colon, stomach, bladder, uterus, rectum, thyroid, and kidney carcinomas [7]. Symptoms related to bone metastasis include pain, fractures, spinal cord compression, and hypercalcemia leading to poor quality of life and reduced life expectancy. It is estimated that the appearance of bone metastasis can reduce the five-years 
survival rate of breast cancer patients from $98 \%$ to $26 \%$ and that of prostate cancer patients from $100 \%$ to $33 \%$ [8].

Both primary and secondary cancers involving the skeleton can cause osteoblastic (sclerotic) or osteolytic lesions, although generally the final histological picture is a mixture of the two. Osteoblastic lesions originate from proliferation of osteoblasts, while osteolytic lesions are generally due to osteoclast activation caused by factors secreted by cancer cells. Common sites of metastasis in the skeleton are the spine, rib cage, limbs and skull. Once settled into the bone, tumor cells release factors that activate matrix resorption leading to bone destruction; this facilitates cancer spread and proliferation $[8,9]$. Since bone resorption activity is followed by an increase in bone formation, as it occurs in normal remodeling, these two processes are intimately linked and typically present at sites of bone metastasis. Osteolytic metastasis are common in breast cancer, mainly due to stimulation by tumor cells of osteoclast differentiation and activity [10]. An associated local bone formation usually occurs, presumably in an attempt to activate repair, but this response is often inefficient, thus leading to final bone loss. In multiple myeloma tumor cells in the bone marrow cause exclusively osteolytic lesions, with almost complete absence of bone formation [4]. This seems to be due to suppression of osteoblast activity. On the contrary, prostate cancer metastasis are primarily osteoblastic, with possible presence of osteolytic components [11]. Most of the factors implicated in osteolytic metastatization are also involved in the pathogenesis of osteoporosis to the point that pharmacological treatment of osteolytic metastasis and osteoporosis is similar.

PTHrP (parathormone-related protein) and TGF- $\beta$ (transforming growth factor beta) are among the most important osteolytic mediators [9]. PTHrP secreted by breast cancer and other tumors, is a well-known potent stimulator of osteoclast activity in bone metastasis. PTHrP acts through the release of RANKL (receptor activator of nuclear factor $\mathrm{kB}$ ligand) which binds to RANK receptor on osteoclasts, the system RANK-RANKL being the main pathway for osteoclast differentiation and activation. Factors released by metastatic cells or by the primary tumor activate bone resorption, this in turn triggers release of TGF- $\beta$ from bone matrix. TGF- $\beta$ and tumor-derived PTHrP are believed to act in a vicious cycle of local bone destruction in osteolytic metastasis: TGF$\beta$ released in active form during osteoclastic resorption of bone matrix stimulates PTHrP production by tumor cells. In turn, PTHrP mediates bone destruction by stimulating osteoclasts $[4,12]$. Furthermore, TGF- $\beta$ released from bone exerts suppressive effects on T lymphocytes and NK cells, thus reducing immune cell response to tumor [13].

Growth of primary bone tumors and development of bone metastasis are complex processes involving bone-tumor cells crosstalk mediated by several different cytokines and growth factors. In this context the study of molecules moulding tumor micro-environment is of great importance for a better understanding of cancer biology and to find new and efficacious therapies. Here we suggest a possible role of extracellular ATP and its receptor P2X7 in the development of both primary bone cancers and skeletal metastasis.

\section{Role of ATP and P2X7 Receptors in Cell Growth and Carcinogenesis}

In recent years investigation of tumor microenvironment has gained great importance for the understanding of tumor formation and progression [14]. Several molecules are released by tumor cells, acting as promoters of proliferation, allowing for immune system escape, helping cell matrix infiltration, neovascularization and distant site invasion. Interestingly, mediators of inflammatory-immune response can also influence cancer progression [15]. A good candidate molecule for many of these functions is extracellular ATP. This nucleotide has been recently shown to accumulate both at inflammatory sites $[16,17]$ and into the interstitium of solid tumors of different origin [18]. ATP release by dying tumor cells, following chemotherapy, is also associated to immunogenic cell death [19]. Immunogenic cell death implies that the host immune system is essential for antitumor effect of certain chemotherapeutic agents such as anthracyclines, and that molecules released from dying tumor cells act as danger signals to activate the host immune response. In this context ATP released from neoplastic cells drives recruitment of dendritic cells and T lymphocytes into the tumor site $[20,21]$. Effects of ATP are mediated by two families of plasma membrane purinergic receptors: P2Y, metabotropic G coupled receptors, and P2X, ligand gated ion channels [22]. The $\mathrm{P} 2 \mathrm{X} 7$ receptor is involved in many of the tumor-promoting and immune-modulatory effects of extracellular ATP. Like other members of the P2X family, P2X7 mediates cation fluxes across the plasma membrane but thanks to its peculiar $\mathrm{C}$ terminal tail it also gates a large nonselective pore [23]. Opening of this pore is coupled to the well-known P2X7 cytotoxic activity usually triggered by high (i.e. $\mathrm{mM}$ ) pharmacological ATP concentrations. On the contrary, basal tonic P2X7 activation mediated by endogenous ATP release causes cell proliferation [24, 25]. Proliferation and other tumor transformation hallmarks seem to be dependent on the channel activity since they are retained also by cells expressing a C-terminal truncated P2X7 splice variant, which lacks pore-forming activity [26]. Several reports suggest an association between P2X7 and cancer [27]. In different cell models P2X7 expression supports organellar calcium increase, NFATc1 activation, matrix infiltration and cell growth [24-26, 28, 29]. There is good evidence that $\mathrm{P} 2 \mathrm{X} 7$ receptor can influence energy production by increasing mitochondrial potential and intracellular ATP levels [25], a condition linked to the PI3 K/Akt pathway that positively influences cell proliferation [30]. Moreover, P2X7 activation alters the biochemical composition of tumor by causing release of microvescicles $[31,32]$ and secretion of cytokines [33], tissue factor [34], matrix metalloproteases (MMPs) [35] and prostaglandins [36]. Furthermore, P2X7 itself can be a conduit for ATP release [37]. Direct participation of $\mathrm{P} 2 \mathrm{X} 7$ in tumor progression was demonstrated in a recent in vivo study by our laboratory [38]. We showed that P2X7 inhibition by either pharmacological tools or RNA interference caused a dramatic reduction of tumor masses, and vice-versa that $\mathrm{P} 2 \mathrm{X} 7$ overexpression accelerated tumor growth. Interestingly P2X7 expressing tumors showed a 
thicker vascular network and higher secretion of vascular endothelial growth factor (VEGF). Accordingly, tumor growth was inhibited by administration of the anti-VEGF antibody bevacizumab [38].

\section{Extracellular ATP and P2X7 as Modulators of Osteoblasts and Osteoclasts Responses}

The role of P2X7 receptor in bone cells has been extensively studied and was recently appraised in several reviews [3942]. P2X7 receptor is expressed by both osteoblasts [43] and osteoclasts $[44,45]$ of different species and plays a central role in mediating osteoblast-osteoclasts crosstalk via calcium oscillations [46] and other signaling pathways [39]. One of the main roles attributed to P2X7 receptor in osteoblasts is to promote cell growth and osteodeposition [36] through a series of different pathways including c-fos [47], ERK [48], PI3 K [49], and COX [36]. Moreover, P2X7 likely mediates osteoblast ATP release as shown by the inhibitory effect on nucleotide release of P2X7 blockers [50, 51].

Skeletal disorders, such as osteoporosis and tumorinduced bone resorption, are caused by increased activity of bone-resorbing osteoclasts. The role of P2X7 in osteoclast biology is still poorly understood. It has been suggested that P2X7 participates in cell fusion, a central step in osteoclastogenesis $[52,53]$, but osteoclasts from P2X7 KO mice are normal in number and size [54, 55]. P2X7 receptor might, however exert its activity on osteoclast fusion indirectly by extracellular adenosine generation [53] or, simply, by increasing survival via RANKL [44] and NF- $\kappa$ B [56] pathways. The effect of P2X7 knock-down on bone phenotype probably depends on the different mice models considered [57]. Whatever is the role of P2X7 in osteoclast fusion and activation, a reduced activity of the receptor has been associated to increased susceptibility to osteoporosis [58]. All the known polymorphisms of human P2X7 have now been studied in different postmenopausal women cohorts [5961 ]. These studies revealed an association between different complications of osteoporosis and loss of function of P2X7; a lower incidence of vertebral fractures in women expressing a gain of function receptor polymorphism was also evident [60]. These data suggest that, depending on the P2X7 polymorphism carried, one could be more or less exposed to osteolytic bone cancer complications.

\section{P2X7 and Cell Metabolism in Cancer: Warburg Effect and Signaling}

Ability to adapt to unfavorable conditions is a key feature of cancer cells, making them more and more aggressive. Tumorcell survival runs through a reorganization of metabolic pathways to balance energy generation and production of biosynthetic intermediates. Aerobic glycolysis (also known as "Warburg effect") is known to be the preferred metabolic path adopted by cancer cells, in presence of oxygen. Lactate release, as a consequence of glucose degradation, is observed in many solid tumors and leukemias. Detection of increased glucose uptake in tissues is commonly used for diagnosis of cancer by positron emission tomography (PET) [62]. In a recent paper, Grol and colleagues showed that in the osteoblast like MC3T3-E1 cell line, P2X7 activation triggers, via PI3 K, release of lactate and increased glucose metabolism [49]. PI3 K activates the serine threonine kinase Akt, one of the most studied paths involved in tumor progression and aggressiveness [63, 64]. Indeed, activation of PI3 K/Akt pathway has been correlated with many cellular critical events such as proliferation, apoptosis, metabolism, adhesion, cytoskeleton modifications, tumorigenesis, metastatization, and drugs resistance $[65,66]$. A direct effect of P2X7 activation on Akt has been shown in several cell lines [30, 67-72]. In some models such as neuroblastoma [70] and non-small-cell lung cancer [72], P2X7 was reported to reduce Akt phosphorylation while in others such as astrocytes [68], neurons $[69,73]$, and osteoblasts [49], the P2X7-Akt axis promoted proliferation and survival. Another Akt-mediated effect during tumor development is induction of HIF- $1 \alpha$ that in turn leads to VEGF production and neovascularization $[74,75]$. One might speculate that P2X7-mediated VEGF secretion from tumoral masses [38] could be dependent on PI3 K/Akt also in tumor proliferating osteoblasts; VEGF being a known positive regulator of osteoblastic lesions [76].

\section{P2X7 Receptor in Primary Bone Tumors}

A search of EMBL-EBI Atlas database (http://www.ebi.ac .uk/) revealed an association between P2X7 overexpression and different malignancies including blood and bone tumors [77]. In particular, P2X7 expression was increased in osteosarcoma, Ewing's sarcoma, chondromyxoid fibroma, and multiple myeloma. Moreover, P2X7 receptor was found to be expressed and active in multiple myeloma cell lines where it mediates MMPs activation [78].

Osteoblasts and osteosarcoma were among the first cell models in which a proliferative activity of P2X7 and ATP was suggested [36]. Although direct in vivo proof of an oncogenic role of the receptor in osteosarcoma is missing, several experimental findings point to such an involvement. Osteoblast like (MC3T3-E1) and osteosarcoma cells lines (SaOs-2, HOS) generally show high expression of P2X7 at mRNA, protein, and functional level $[43,79,80]$. P2X7 is expressed in MSC osteoblastic precursors [81] and is highly and constantly detected during osteoblast differentiation [82]. P2X7 activity has been associated to proliferation and osteodeposition [36] as well as to upmodulation of the osteosclerotic factor FosB [83] in osteoblasts [84]. In a recent study, Liu and Chen demonstrated a trophic effect of ATP on HOS cells that was abolished by suramin, a P2 purinoceptors antagonist. Suramin also inhibited ATP-dependent cytosolic calcium increases.The ATP growth promoting effect was likely mediated via both P2X4 and P2X7 [80]. A role for $\mathrm{P} 2 \mathrm{X} 7$ receptor in osteoblasts proliferation and osteogenesis was also indicated by Panupinthu et al. who reported reduced cell growth and osteodeposition by calvarial cell cultures from P2X7 KO mice [36]. P2X7 activated pathways in osteoblasts include cyclooxygenase (COX), lysophosphatidic acid, and prostaglandin E2 [36]. A further study by Gavala et 
al. showed that P2X7 dependent AP-1/Fos-B activation was responsible for COX-2 expression [84]. Moreover, mechanical stimulation triggers ATP release and P2X7-dependent activation of several kinases, including ERK [48] and PI3 K [49]. It is tempting to speculate that a condition, such as cancer, in which extracellular ATP levels are known to be upregulated [18], might mimic mechanical loading causing and stimulating osteoblast proliferation. Furthermore, mouse osteoblasts and osteoclasts constitutively release ATP into extracellular microenvironment via P2X7-dependent pathway [51].

NFAT is one of the main pathways activated through $\mathrm{Ca}^{2+}$ and calcineurin following P2X7 stimulation [29, 85-88]. We have shown that NFATc1 activation is central for P2X7 trophic activity as treatment with the NFATc1 inhibitors cyclosporine and VIVIT obliterates P2X7-dependent cell growth [29]. Moreover, P2X7-positive tumors overexpress NFATc1 [38]. On the other hand NFAT has a central role also in osteoblast biology. Mice expressing in osteoblasts a constitutively nuclear NFATc1 variant, NFATc1(nuc), develop bone masses characterized by osteoblast overgrowth [89]. Accordingly, viable NFATc1-deficient mice have defects in bone formation, in addition to impaired osteoclast development. Calcineurin/NFAT-signaling in Osteoblasts controls the expression of chemoattractants for monocytic osteoclast precursors, thereby coupling bone formation and bone resorption, and regulating bone mass [89]. Elevated levels of NFAT are among factors necessary for in vitro invasiveness of mice metastatic osteosarcoma cell lines [90]. Finally, calcineurin/NFAT pathway is implicated in prostate cancer bone metastasis. Prostate tumor cells that engraft in the bone stimulate osteoblasts by secreting growth-promoting factors among which endothelin 1 (ET-1). In osteoblasts ET1 activates calcineurin, causes nuclear translocation of NFAT and, thus, osteoblasts stimulation [91]. On the other hand, a negative role for NFAT in osteoblasts has been proposed by Choo et al. who demonstrated that constitutively active NFAT inhibits alkaline phosphatase activity and mineralization [92]. These observations might suggest that P2X7 could cause NFAT activation and osteoblast proliferation both in primary and metastatic osteoblastic lesions.

Moreover, $\mathrm{Ca}^{2+}$-NFAT signaling is essential for osteoclast differentiation [93]. Intriguingly, NFAT activation in osteoclasts has also been related to malignant progression of multiple myeloma. Several studies reported osteoblast NFAT reduction associated with decreased osteoclastogenesis, following myeloma treatment [94-97].

P2X7 was shown to induce ATP secretion from both osteoclasts and osteoblasts [51]. Increase in extracellular ATP is followed by extracellular adenosine accumulation viaCD39 and CD73 ectonucleotidases [98]. Adenosine was demonstrated to stimulate proliferation of MC3T3-E1 osteoblasticlike cell line [99]. Furthermore, HCC1 cells release increased amounts of IL-6 and osteoprotegerin following adenosine receptor stimulation [100], likely modulating osteoclastogenesis and bone resorption.

VEGF production was found increased in different experimental tumors expressing $\mathrm{P} 2 \mathrm{X} 7$ receptor [38]. The $\mathrm{P} 2 \mathrm{X} 7-\mathrm{VEGF}$ connection in tumors is also supported by the finding that P2X7 activation in rat C6 glioma cells is linked to increased release of proinflammatory factors (MCP-1, IL-8 and VEGF) and to tumor-cell migration [101]. Accordingly, patients with osteosarcoma showed increased VEGF plasma levels, and this was reduced following tumor removal by surgery [102]. Moreover, VEGF secretion is known to be central in malignant progression of multiple myeloma; the first lymphohaemopoietic tumor in which increased angiogenesis was detected, and which greatly benefits of the treatment with VEGF-targeted agents [103].

\section{P2X7 Receptor Activity in Bone Metastasizing Cancers}

The complications of bone metastasis are thought to be due to the perturbation of the interaction between osteoblasts and osteoclasts. This disruption is thought to be caused by tumor-derived humoral mediators produced by the metastasized cancer cells within the bone marrow. Among factors regulating bone cancer metastasis RANKL plays a central role, as demonstrated by the efficacy of an anti-RANKL antibody in the therapy of such secondary tumors [104]. During physiological bone remodeling RANKL, produced by proliferating osteoblasts, causes activation of osteoclasts ensuring a balance between osteodeposition and bone resorption. However, the presence of cancer cells can alter bone microenvironment causing an increased production of RANKL, favoring osteoclasts activation and osteolysis. Several factors, such as IL-1, IL-6, COX2/prostaglandins, and VEGF, can cause positive shifts in RANKL production [10, 105]. All these mediators are released upon $P 2 X 7$ stimulation from different cell types, including osteoblasts [36], immune $[106,107]$, and cancer cells $[38,108,109]$. Moreover, P2X7mediated ATP secretion [26, 37] from tumor cells [18] could itself upregulate osteoblasts RANKL expression [44]. Extracellular ATP is rapidly degraded to adenosine, which can directly modulate osteoclasts formation through A2 receptors [53]. P2X7-dependent Rho-kinase1 (ROCK) activation has been demonstrated in several cell types [31, 110112], including osteoblasts [113]. ROCK is known to activate changes in cell morphology, adhesion, and motility, and is associated to P2X7-dependent cell blebbing, a response that might be related to invasive phenotype of P2X7-expressing cells $[26,38,114]$. Interestingly, an increased ROCK signaling has been shown to contribute to breast cancer invasiveness [115] as, if overexpressed, the kinase conferred a bone metastatic phenotype to a human breast cancer cell line in an in vivo model. ROCK is also known to mediate activation of the proresorptive factor PTHrP through activation of TGF- $\beta$ signaling [116].

Several studies reported an association between primary tumors causing bone metastatization and P2X7 overexpression and function (for a recent review see [27]). Upregulation of P2X7 in breast cancer was shown for the first time by Slater et al. who demonstrated an association between receptor expression and tumor invasiveness [117]. Recently, Jelassi et al. also showed an involvement of P2X7 in breast cancer metastasis formation [114]. P2X7 activation in a 
highly aggressive breast cancer cell line (MDA-MB-435s) caused increased in vitro cell motility and extracellular matrix infiltration [114]. Accordingly, P2X7 inhibition significantly reduced in vivo cell migration in a zebra fish embryo metastatic model [114]. As previously reported in macrophages [118], P2X7 receptor activation caused release of a broad range of cathepsins, including cathepsin $\mathrm{k}$, also from breast cancer cells [114]. Another bone-degrading enzyme which is secreted in a P2X7-dependent fashion is MMP9 [35]. Cathepsin $\mathrm{k}$ and MPPs release in resorption pits during bone degradation make these enzymes attractive therapeutic targets to block osteolysis [11]. Since cathepsin $\mathrm{k}$ inhibitors showed adverse effects during clinical trials [11], pharmacological inhibition of upstream pathways, such as P2X7, could prove useful in therapy.

A peculiar case of tumor causing osteolytic metastasis is neuroblastoma, which is the second most common pediatric malignancy worldwide and is responsible for $15 \%$ of childhood cancer deaths [119]. Patients with high-risk metastatic disease (stages III-IV) show a mere $42 \%$ survival rate, despite treatment [120]. Few years ago Raffaghello et al. showed that P2X7 receptor is expressed in specimens from neuroblastoma patients and in all neuroblastoma cell lines examined [109]. Interestingly, in these cells P2X7 receptor lacks its well-known cytotoxic activity but rather supports proliferation [109]. Wu et al. have recently reported expression of P2X7 also in murine neuroblastoma cell lines [121]. In these cells P2X7 inhibits differentiation [121], promotes proliferation [70], and microvesicles release [122]. $\mathrm{P} 2 \mathrm{X} 7$ implication in neuroblastoma progression is further supported from in vivo experiments from our laboratory showing a 2-3 fold reduction in neuroblastoma tumor masses upon P2X7 silencing [38]. Bone involvement is observed in $55-68 \%$ of neuroblastoma patients who present metastatic disease at diagnosis [123], particularly at the bony orbit. Bone metastasis is generally associated with osteolytic lesions due to either direct action of cancer cells on osteoclasts or to an indirect involvement of osteoblasts finally causing bone resorption [123]. Although direct evidence of P2X7 involvement in neuroblastoma bone metastatization is still missing all experimental evidence points to such an association $[38,53,109]$.

Patients with advanced prostate carcinoma generally develop osteoblastic metastasis due to deregulation of physiological bone remodeling. In these patients prostate cancer cells are adjacent to large numbers of osteoblasts, which are responsible for woven bone deposition [76]. P2X7 expression by prostate cancer cells has been reported long time ago $[124,125]$. Furthermore, ATP treatment increases prostate cancer cell invasion [126]. The cross-talk between prostate cancer cells and osteoblasts contributes to metastatic development. If on one hand cancer cells secrete TGF $\beta$, VEGF and other factors promoting osteoblast proliferation and differentiation, on the other osteoblasts can prompt cancer cells to secrete MMP9 and stimulate tumor cell growth [76]. P2X7 activation has been involved in secretion of almost all the above factors either from osteoblasts [44] or from cancer cells $[35,38]$.

\section{Conclusions and Future Perspectives}

Over-expression of a potentially cytotoxic receptor such as P2X7 by cancer cells is puzzling. However, the discovery that this receptor has oncogene-like properties may provide a logical explanation for this finding $[38,114]$. Due to altered skeletal phenotype of P2X7 KO mice, bone has been one of the tissues in which P2X7 activity has been best characterized. Nevertheless, there is only sporadic evidence linking bone related cancers and P2X7 so far. Here we propose that $\mathrm{P} 2 \mathrm{X} 7$ might have a central role in bone cancer development and progression by causing NFATc1, PI3K/Akt, ROCK, VEGF activation, thus driving osteoblast proliferation in primary bone tumors and osteoblastic metastasis. P2X7 might also stimulate bone resorption by causing osteoclast activation [53] as well as secretion of cathepsins and MMPs $[35,114]$ thus contributing to osteolytic metastasis formation.

The processes of bone resorption and bone formation are tightly coupled and treatments that primarily target the osteoclasts generally exert secondary inhibitory effects on bone formation. The discovery of new pathways occurring in tumorigenic transformation and aggressiveness of bonerelated cancers made clinicians pay attention to new targeting drugs: blocking bone lesions acting on osteoblasts/osteoclasts regulation, like bisphosphonates do, is not the only chance anymore. Clinical trials with RANKL blocking antibody (denosumab) produced very encouraging results showing that denosumab was tolerated better than bisphosphonates (zolendronic acid) and even increased patient survival [104]. Inhibitors of mTOR, an Akt downstream effector are in clinical trials for the treatment of multiple bone related cancers [127]. In particular, rapamycin is known to arrest cell growth in osteosarcoma $[128,129]$ and breast cancer [130].

Since P2X7 receptor is an upstream regulator of all the paths inhibited by the RANKL and mTOR blockers, it is an attractive therapeutic target for bone-related diseases too. Several P2X7 antagonists are currently in phase I and II clinical trials for the treatment of chronic inflammatory diseases, showing so far excellent safety profiles [131]. These drugs are, in principle, available to be used at patient's bed and could be a good therapeutic opportunity for those cancers, such as neuroblastoma and multiple myeloma, which still lack an efficacious cure.

\section{Acknowledgments}

The authors are deeply indebted to Professor Francesco Di Virgilio for discussing and revising the manuscript. They also thank Drs. Simonetta Falzoni and Marina Capece for critical reading. The authors are grateful to Drs Alvis Brazma and Margus Lukk for helping them with interpretation of Affimetrix data accessible through the Atlas database. This work was supported by a Grant from the Italian Association for Cancer Research (AIRC) to E. Adinolfi (MFAG 11630). E. Adinolfi and A. L. Giuliani are members of the ATP Bone European Consortium. 


\section{References}

[1] M. Hameed and H. Dorfman, "Primary malignant bone tumors-recent developments," Seminars in Diagnostic Pathology, vol. 28, no. 1, pp. 86-101, 2011.

[2] G. Ottaviani and N. Jaffe, "The epidemiology of osteosarcoma," Cancer Treatment and Research, vol. 152, pp. 3-13, 2009.

[3] G. Ottaviani and N. Jaffe, "The etiology of osteosarcoma," Cancer Treatment and Research, vol. 152, pp. 15-32, 2009.

[4] G. D. Roodman, "Osteoblast function in myeloma," Bone, vol. 48, no. 1, pp. 135-140, 2011.

[5] D. Atanackovic, Y. Cao, T. Luetkens et al., "CD4 ${ }^{+}$ $\mathrm{CD}_{25}{ }^{+} \mathrm{FOXP}^{+} \mathrm{T}$ regulatory cells reconstitute and accumulate in the bone marrow of patients with multiple myeloma following allogeneic stem cell transplantation," Haematologica, vol. 93, no. 3, pp. 423-430, 2008.

[6] K. C. Anderson, "New insights into therapeutic targets in myeloma," American Society of Hematology Education Program, pp. 184-190, 2011.

[7] N. Kinnane, "Burden of bone disease," European Journal of Oncology Nursing, vol. 11, supplement 2, pp. S28-S31, 2007.

[8] A. Mishra, Y. Shiozawa, K. J. Pienta, and R. S. Taichman, "Homing of cancer cells to the bone," Cancer Microenvironment, vol. 4, no. 3, pp. 221-235, 2011.

[9] L. J. Suva, C. Washam, R. W. Nicholas, and R. J. Griffin, "Bone metastasis: mechanisms and therapeutic opportunities," Nature Reviews Endocrinology, vol. 7, no. 4, pp. 208218, 2011.

[10] Y. C. Chen, D. M. Sosnoski, and A. M. Mastro, "Breast cancer metastasis to the bone: mechanisms of bone loss," Breast Cancer Research, vol. 12, no. 6, p. 215, 2010.

[11] J. Sturge, M. P. Caley, and J. Waxman, "Bone metastasis in prostate cancer: emerging therapeutic strategies," Nature Reviews Clinical Oncology, vol. 8, no. 6, pp. 357-368, 2011.

[12] T. A. Guise, K. S. Mohammad, G. Clines et al., "Basic mechanisms responsible for osteolytic and osteoblastic bone metastases," Clinical Cancer Research, vol. 12, no. 20, part 2, pp. 6213s-6216s, 2006.

[13] P. G. J. Fournier, J. M. Chirgwin, and T. A. Guise, "New insights into the role of $\mathrm{T}$ cells in the vicious cycle of bone metastases," Current Opinion in Rheumatology, vol. 18, no. 4, pp. 396-404, 2006.

[14] A. Mantovani, "Molecular pathways linking inflammation and cancer," Current Molecular Medicine, vol. 10, no. 4, pp. 369-373, 2010.

[15] M. Allen and J. L. Jones, "Jekyll and Hyde: the role of the microenvironment on the progression of cancer," Journal of Pathology, vol. 223, no. 2, pp. 162-176, 2011.

[16] F. C. Weber, P. R. Esser, T. Müller et al., "Lack of the purinergic receptor $\mathrm{P} 2 \mathrm{X} 7$ results in resistance to contact hypersensitivity," Journal of Experimental Medicine, vol. 207, no. 12, pp. 2609-2619, 2010.

[17] K. Wilhelm, J. Ganesan, T. Müller et al., "Graft-versus-host disease is enhanced by extracellular ATP activating P2X7R," Nature Medicine, vol. 16, no. 12, pp. 1434-1439, 2010.

[18] P. Pellegatti, L. Raffaghello, G. Bianchi, F. Piccardi, V. Pistoia, and F. Di Virgilio, "Increased level of extracellular ATP at tumor sites: in vivo imaging with plasma membrane luciferase," PLoS ONE, vol. 3, no. 7, Article ID e2599, 2008.

[19] M. Michaud, I. Martins, A. Sukkurwala et al., "Autophagydependent anticancer immune responses induced by chemotherapeutic agents in mice," Science, vol. 334, no. 6062, pp. 1573-1577, 2011.
[20] F. Ghiringhelli, L. Apetoh, A. Tesniere et al., "Activation of the NLRP3 inflammasome in dendritic cells induces IL$1 \beta$-dependent adaptive immunity against tumors," Nature Medicine, vol. 15, no. 10, pp. 1170-1178, 2009.

[21] I. Martins, M. Michaud, A. Q. Sukkurwala et al., "Premortem autophagy determines the immunogenicity of chemotherapy-induced cancer cell death," Autophagy. In press.

[22] G. Burnstock, "Discovery of purinergic signalling, the initial resistance and current explosion of interest," British Journal of Pharmacology. In press.

[23] A. Surprenant, F. Rassendren, E. Kawashima, R. A. North, and G. Buell, "The cytolytic P2Z receptor for extracellular ATP identified as a P2X receptor (P2X7)," Science, vol. 272, no. 5262, pp. 735-738, 1996.

[24] O. R. Baricordi, L. Melchiorri, E. Adinolfi et al., "Increased proliferation rate of lymphoid cells transfected with the P2X7 ATP receptor," Journal of Biological Chemistry, vol. 274, no. 47, pp. 33206-33208, 1999.

[25] E. Adinolfi, M. G. Callegari, D. Ferrari et al., "Basal activation of the P2X7 ATP receptor elevates mitochondrial calcium and potential, increases cellular ATP levels, and promotes serum-independent growth," Molecular Biology of the Cell, vol. 16, no. 7, pp. 3260-3272, 2005.

[26] E. Adinolf, M. Cirillo, R. Woltersdorf et al., "Trophic activity of a naturally occurring truncated isoform of the P2X7 receptor," FASEB Journal, vol. 24, no. 9, pp. 3393-3404, 2010.

[27] F. Di Virgilio, D. Ferrari, and E. Adinolfi, "P2X7: a growthpromoting receptor-implications for cancer," Purinergic Signalling, vol. 5, no. 2, pp. 251-256, 2009.

[28] E. Adinolfi, C. Pizzirani, M. Idzko et al., "P2X7 receptor: death or life?" Purinergic Signalling, vol. 1, no. 3, pp. 219-227, 2005.

[29] E. Adinolfi, M. G. Callegari, M. Cirillo et al., "Expression of the $\mathrm{P} 2 \mathrm{X} 7$ receptor increases the $\mathrm{Ca}^{+}$content of the endoplasmic reticulum, activates NFATc1, and protects from apoptosis," Journal of Biological Chemistry, vol. 284, no. 15, pp. 10120-10128, 2009.

[30] O. Mistafa and U. Stenius, "Statins inhibit Akt/PKB signaling via P2X7 receptor in pancreatic cancer cells," Biochemical Pharmacology, vol. 78, no. 9, pp. 1115-1126, 2009.

[31] A. B. Mackenzie, M. T. Young, E. Adinolfi, and A. Surprenant, "Pseudoapoptosis induced by brief activation of ATP-gated P2X7 receptors," Journal of Biological Chemistry, vol. 280, no. 40, pp. 33968-33976, 2005.

[32] C. Pizzirani, D. Ferrari, P. Chiozzi et al., "Stimulation of P2 receptors causes release of IL- $1 \beta$-loaded microvesicles from human dendritic cells," Blood, vol. 109, no. 9, pp. 3856-3864, 2007.

[33] D. Ferrari, C. Pizzirani, E. Adinolfi et al., "The P2X7 receptor: a key player in IL-1 processing and release," Journal of Immunology, vol. 176, no. 7, pp. 3877-3883, 2006.

[34] M. Baroni, C. Pizzirani, M. Pinotti et al., "Stimulation of P2 (P2X7) receptors in human dendritic cells induces the release of tissue factor-bearing microparticles," FASEB Journal, vol. 21, no. 8, pp. 1926-1933, 2007.

[35] B. J. Gu and J. S. Wiley, "Rapid ATP-induced release of matrix metalloproteinase 9 is mediated by the $\mathrm{P} 2 \mathrm{X} 7$ receptor," Blood, vol. 107, no. 12, pp. 4946-4953, 2006.

[36] N. Panupinthu, J. T. Rogers, L. Zhao et al., "P2X7 receptors on osteoblasts couple to production of lysophosphatidic acid: a signaling axis promoting osteogenesis," Journal of Cell Biology, vol. 181, no. 5, pp. 859-871, 2008. 
[37] P. Pellegatti, S. Falzoni, P. Pinton, R. Rizzuto, and F. Di Virgilio, "A novel recombinant plasma membrane-targeted luciferase reveals a new pathway for ATP secretion," Molecular Biology of the Cell, vol. 16, no. 8, pp. 3659-3665, 2005.

[38] E. Adinolfi, L. Raffaghello, A. L. Giuliani et al., "Expression of P2X7 receptor increases in vivo tumor growth," Cancer Research, vol. 72, no. 12, pp. 2957-2969, 2012.

[39] M. W. Grol, N. Panupinthu, J. Korcok, S. M. Sims, and S. J. Dixon, "Expression, signaling, and function of P2X7 receptors in bone," Purinergic Signalling, vol. 5, no. 2, pp. 205-221, 2009.

[40] J. P. Reyes, S. M. Sims, and S. J. Dixon, "P2 receptor expression, signaling and function in osteoclasts," Frontiers in Bioscience, vol. 3, pp. 1101-1118, 2011.

[41] A. Gartland, I. R. Orriss, R. M. Rumney, A. P. Bond, T. Arnett, and J. A. Gallagher, "Purinergic signalling in osteoblasts," Frontiers in Bioscience, vol. 17, pp. 16-29, 2012.

[42] I. Lemaire, S. Falzoni, and E. Adinolfi, "Purinergic signaling in giant cell formation," Frontiers in Bioscience, vol. 4, pp. 41$55,2012$.

[43] A. Gartland, R. A. Hipskind, J. A. Gallagher, and W. B. Bowler, "Expression of a P2X7 receptor by a subpopulation of human osteoblasts," Journal of Bone and Mineral Research, vol. 16, no. 5, pp. 846-856, 2001.

[44] K. A. Buckley, R. A. Hipskind, A. Gartland, W. B. Bowler, and J. A. Gallagher, "Adenosine triphosphate stimulates human osteoclast activity via upregulation of osteoblast-expressed receptor activator of nuclear factor- $\kappa \mathrm{B}$ ligand," Bone, vol. 31 , no. 5, pp. 582-590, 2002.

[45] A. Gartland, K. A. Buckley, R. A. Hipskind, W. B. Bowler, and J. A. Gallagher, "P2 receptors in bone-modulation of osteoclast formation and activity via P2X7 activation," Critical Reviews in Eukaryotic Gene Expression, vol. 13, no. 2-4, pp. 237-242, 2003.

[46] N. R. Jørgensen, Z. Henriksen, O. H. Sørensen, E. F. Eriksen, R. Civitelli, and T. H. Steinberg, "Intercellular calcium signaling occurs between human osteoblasts and osteoclasts and requires activation of osteoclast $\mathrm{P} 2 \mathrm{X} 7$ receptors," Journal of Biological Chemistry, vol. 277, no. 9, pp. 7574-7580, 2002.

[47] H. Okumura, D. Shiba, T. Kubo, and T. Yokoyama, "P2X7 receptor as sensitive flow sensor for ERK activation in osteoblasts," Biochemical and Biophysical Research Communications, vol. 372, no. 3, pp. 486-490, 2008.

[48] D. Liu, D. C. Genetos, Y. Shao et al., "Activation of extracellular-signal regulated kinase (ERK1/2) by fluid shear is $\mathrm{Ca}^{+}$- and ATP-dependent in MC3T3-E1 osteoblasts," Bone, vol. 42, no. 4, pp. 644-652, 2008.

[49] M. W. Grol, I. Zelner, and S. J. Dixon, "P2X-mediated calcium influx triggers a sustained, PI3K-dependent increase in metabolic acid production by osteoblast-like cells," American Journal of Physiology, vol. 302, no. 5, pp. E561-E575, 2012.

[50] R. M. Rumney, A. Sunters, G. C. Reilly, and A. Gartland, "Application of multiple forms of mechanical loading to human osteoblasts reveals increased ATP release in response to fluid flow in $3 \mathrm{D}$ cultures and differential regulation of immediate early genes," Journal of Biomechanics, vol. 45, no. 3, pp. 549-554, 2012.

[51] A. Brandao-Burch, M. L. Key, J. J. Patel, T. R. Arnett, and I. R. Orriss, "The P2X7 receptor is an important regulator of extracellular ATP levels," Frontiers in Endocrinology, vol. 3, article 41, 2012.

[52] A. Gartland, K. A. Buckley, W. B. Bowler, and J. A. Gallagher, "Blockade of the pore-forming P2X7 receptor inhibits formation of multinucleated human osteoclasts in vitro," Calcified Tissue International, vol. 73, no. 4, pp. 361369, 2003.

[53] P. Pellegatti, S. Falzoni, G. Donvito, I. Lemaire, and F. Di Virgilio, "P2X7 receptor drives osteoclast fusion by increasing the extracellular adenosine concentration," FASEB Journal, vol. 25, no. 4, pp. 1264-1274, 2011.

[54] H. Z. Ke, H. Qi, A. F. Weidema et al., "Deletion of the $\mathrm{P} 2 \mathrm{X} 7$ nucleotide receptor reveals its regulatory roles in bone formation and resorption," Molecular Endocrinology, vol. 17, no. 7, pp. 1356-1367, 2003.

[55] A. Gartland, K. A. Buckley, R. A. Hipskind et al., "Multinucleated osteoclast formation in vivo and in vitro by P2X 7 receptor-deficient mice," Critical Reviews in Eukaryotic Gene Expression, vol. 13, no. 2-4, pp. 243-253, 2003.

[56] J. Korcok, L. N. Raimundo, H. Z. Ke, S. M. Sims, and S. J. Dixon, "Extracellular nucleotides act through P2X7 receptors to activate NF- $\kappa \mathrm{B}$ in osteoclasts," Journal of Bone and Mineral Research, vol. 19, no. 4, pp. 642-651, 2004.

[57] I. Orriss, S. Syberg, N. Wang et al., "Bone phenotypes of P2 receptor knockout mice," Frontiers in Bioscience, vol. 3, pp. 1038-1046, 2011.

[58] A. Wesselius, M. J. L. Bours, A. Agrawal et al., "Role of purinergic receptor polymorphisms in human bone," Frontiers in Bioscience, vol. 17, pp. 2572-2585, 2011.

[59] S. D. Ohlendorff, C. L. Tofteng, J. E. B. Jensen et al., "Single nucleotide polymorphisms in the $\mathrm{P} 2 \mathrm{X} 7$ gene are associated to fracture risk and to effect of estrogen treatment," Pharmacogenetics and Genomics, vol. 17, no. 7, pp. 555-567, 2007.

[60] A. Gartland, K. K. Skarratt, L. J. Hocking et al., "Polymorphisms in the P2X7 receptor gene are associated with low lumbar spine bone mineral density and accelerated bone loss in post-menopausal women," European Journal of Human Genetics, vol. 20, no. 5, pp. 559-564, 2012.

[61] N. R. Jorgensen, L. B. Husted, K. K. Skarratt et al., "Singlenucleotide polymorphisms in the $\mathrm{P} 2 \mathrm{X} 7$ receptor gene are associated with post-menopausal bone loss and vertebral fractures," European Journal of Human Genetics, vol. 20, no. 6, pp. 675-681, 2012.

[62] M. G. V. Heiden, L. C. Cantley, and C. B. Thompson, "Understanding the warburg effect: the metabolic requirements of cell proliferation," Science, vol. 324, no. 5930, pp. 1029-1033, 2009.

[63] M. A. Knowles, F. M. Platt, R. L. Ross, and C. D. Hurst, "Phosphatidylinositol 3-kinase (PI3K) pathway activation in bladder cancer," Cancer and Metastasis Reviews, vol. 28, no. 3-4, pp. 305-316, 2009.

[64] M. Scrima, M. C. De, F. Fabiani et al., "Signaling networks associated with AKT activation in non-small cell lung cancer (NSCLC): new insights on the role of phosphatydil-inositol-3 kinase," PLoS ONE, vol. 7, no. 2, Article ID e30427, 2012.

[65] D. A. Fruman, R. E. Meyers, and L. C. Cantley, "Phosphoinositide kinases," Annual Review of Biochemistry, vol. 67, pp. 481-507, 1998.

[66] L. M. Neri, P. Borgatti, S. Capitani, and A. M. Martelli, "The nuclear phosphoinositide 3-kinase/AKT pathway: a new second messenger system," Biochimica et Biophysica Acta, vol. 1584, no. 2-3, pp. 73-80, 2002.

[67] Y. P. Liu, C. S. Yang, M. C. Chen, S. H. Sun, and S. F. Tzeng, " $\mathrm{Ca} 2{ }^{+}$-dependent reduction of glutamate aspartate transporter GLAST expression in astrocytes by $\mathrm{P} 2 \mathrm{X} 7$ receptormediated phosphoinositide 3-kinase signaling," Journal of Neurochemistry, vol. 113, no. 1, pp. 213-227, 2010.

[68] M. C. Jacques-Silva, R. Rodnight, G. Lenz et al., "P2X7 receptors stimulate AKT phosphorylation in astrocytes," 
British Journal of Pharmacology, vol. 141, no. 7, pp. 11061117, 2004.

[69] F. Ortega, R. Pérez-Sen, E. G. Delicado, and M. T. MirasPortugal, "P2X7 nucleotide receptor is coupled to GSK3 inhibition and neuroprotection in cerebellar granule neurons," Neurotoxicity Research, vol. 15, no. 3, pp. 193-204, 2009.

[70] R. Gómez-Villafuertes, A. Del Puerto, M. Díaz-Hernández et al., "Ca2 + /calmodulin-dependent kinase II signalling cascade mediates P2X7 receptor-dependent inhibition of neuritogenesis in neuroblastoma cells," FEBS Journal, vol. 276, no. 18, pp. 5307-5325, 2009.

[71] O. Mistafa, A. Ghalali, S. Kadekar, J. Högberg, and U. Stenius, "Purinergic receptor-mediated rapid depletion of nuclear phosphorylated Akt depends on pleckstrin homology domain leucine-rich repeat phosphatase, calcineurin, protein phosphatase 2A, and PTEN phosphatases," Journal of Biological Chemistry, vol. 285, no. 36, pp. 27900-27910, 2010.

[72] O. Mistafa, J. Högberg, and U. Stenius, "Statins and ATP regulate nuclear pAkt via the $\mathrm{P} 2 \mathrm{X} 7$ purinergic receptor in epithelial cells," Biochemical and Biophysical Research Communications, vol. 365, no. 1, pp. 131-136, 2008.

[73] R. Pérez-Sen, F. Ortega, V. Morente, E. G. Delicado, and M. T. Miras-Portugal, "P2X7, NMDA and BDNF receptors converge on GSK3 phosphorylation and cooperate to promote survival in cerebellar granule neurons," Cellular and Molecular Life Sciences, vol. 67, no. 10, pp. 1723-1733, 2010.

[74] K. Inoki, M. N. Corradetti, and K. L. Guan, "Dysregulation of the TSC-mTOR pathway in human disease," Nature Genetics, vol. 37, no. 1, pp. 19-24, 2005.

[75] D. A. Altomare and J. R. Testa, "Perturbations of the AKT signaling pathway in human cancer," Oncogene, vol. 24, no. 50, pp. 7455-7464, 2005.

[76] T. Ibrahim, E. Flamini, L. Mercatali, E. Sacanna, P. Serra, and D. Amadori, "Pathogenesis of osteoblastic bone metastases from prostate cancer," Cancer, vol. 116, no. 6, pp. 1406-1418, 2010.

[77] M. Lukk, M. Kapushesky, J. Nikkilä et al., "A global map of human gene expression," Nature Biotechnology, vol. 28, no. 4, pp. 322-324, 2010.

[78] A. W. Farrell, S. Gadeock, A. Pupovac et al., "P2X7 receptor activation induces cell death and CD23 shedding in human RPMI 8226 multiple myeloma cells," Biochimica et Biophysica Acta, vol. 1800, no. 11, pp. 1173-1182, 2010.

[79] S. M. Alqallaf, B. A. J. Evans, and E. J. Kidd, "Atypical P2X7 receptor pharmacology in two human osteoblast-like cell lines," British Journal of Pharmacology, vol. 156, no. 7, pp. 1124-1135, 2009.

[80] P. S. Liu and C. Y. Chen, "Butyl benzyl phthalate suppresses the ATP-induced cell proliferation in human osteosarcoma HOS cells," Toxicology and Applied Pharmacology, vol. 244, no. 3, pp. 308-314, 2010.

[81] N. Zippel, C. A. Limbach, N. Ratajski et al., "Purinergic receptors influence the differentiation of human mesenchymal stem cells," Stem Cells and Development, vol. 21, no. 6, pp. 884-900, 2012.

[82] I. R. Orriss, G. E. Knight, S. Ranasinghe, G. Burnstock, and T. R. Arnett, "Osteoblast responses to nucleotides increase during differentiation," Bone, vol. 39, no. 2, pp. 300-309, 2006.

[83] G. Sabatakos, N. A. Sims, J. Chen et al., "Overexpression of $\triangle$ FosB transcription factor(s) increases bone formation and inhibits adipogenesis," Nature Medicine, vol. 6, no. 9, pp. 985-990, 2000.
[84] M. L. Gavala, L. M. Hill, L. Y. Lenertz, M. R. Karta, and P. J. Bertics, "Activation of the transcription factor FosB/activating protein-1 (AP-1) is a prominent downstream signal of the extracellular nucleotide receptor P2RX7 in monocytic and osteoblastic cells," Journal of Biological Chemistry, vol. 285, no. 44, pp. 34288-34298, 2010.

[85] D. Ferrari, C. Stroh, and K. Schulze-Osthoff, "P2X7/P2Z purinoreceptor-mediated activation of transcription factor NFAT in microglial cells," Journal of Biological Chemistry, vol. 274, no. 19, pp. 13205-13210, 1999.

[86] M. Shiratori, H. Tozaki-Saitoh, M. Yoshitake, M. Tsuda, and K. Inoue, "P2X7 receptor activation induces CXCL2 production in microglia through NFAT and PKC/MAPK pathways," Journal of Neurochemistry, vol. 114, no. 3, pp. 810$819,2010$.

[87] L. Yip, T. Woehrle, R. Corriden et al., "Autocrine regulation of T-cell activation by ATP release and P2X 7 receptors," FASEB Journal, vol. 23, no. 6, pp. 1685-1693, 2009.

[88] A. Kataoka, H. Tozaki-Saitoh, Y. Koga, M. Tsuda, and $\mathrm{K}$. Inoue, "Activation of $\mathrm{P} 2 \mathrm{X} 7$ receptors induces CCL3 production in microglial cells through transcription factor NFAT," Journal of Neurochemistry, vol. 108, no. 1, pp. 115125, 2009.

[89] M. M. Winslow, M. Pan, M. Starbuck et al., "Calcineurin/ NFAT signaling in osteoblasts regulates bone mass," Developmental Cell, vol. 10, no. 6, pp. 771-782, 2006.

[90] P. Velupillai, C. K. Sung, Y. Tian et al., "Polyoma virusinduced osteosarcomas in inbred strains of mice: host determinants of metastasis," PLoS Pathogens, vol. 6, no. 1, Article ID e1000733, 2010.

[91] C. Van Sant, G. Wang, M. G. Anderson, O. J. Trask, R. Lesniewski, and D. Semizarov, "Endothelin signaling in osteoblasts: global genome view and implication of the calcineurin/NFAT pathway," Molecular Cancer Therapeutics, vol. 6, no. 1, pp. 253-261, 2007.

[92] M. K. Choo, H. Yeo, and M. Zayzafoon, "NFATc1 mediates HDAC-dependent transcriptional repression of osteocalcin expression during osteoblast differentiation," Bone, vol. 45, no. 3, pp. 579-589, 2009.

[93] T. Negishi-Koga and H. Takayanagi, "Ca2 ${ }^{+}-\mathrm{NFATc1}$ signaling is an essential axis of osteoclast differentiation," Immunological Reviews, vol. 231, no. 1, pp. 241-256, 2009.

[94] A. Garcia-Gomez, E. M. Ocio, E. Crusoe et al., "Dasatinib as a bone-modifying agent: anabolic and anti-resorptive effects," PLoS ONE, vol. 7, no. 4, Article ID e34914, 2012.

[95] J. Oh, M. S. Lee, J. T. Yeon et al., "Inhibitory regulation of osteoclast differentiation by interleukin-3 via regulation of cFos and Id protein expression," Journal of Cellular Physiology, vol. 227, no. 5, pp. 1851-1860, 2012.

[96] A. Pennisi, W. Ling, X. Li et al., "The ephrinB2/EphB4 axis is dysregulated in osteoprogenitors from myeloma patients and its activation affects myeloma bone disease and tumor growth," Blood, vol. 114, no. 9, pp. 1803-1812, 2009.

[97] H. Yeo, J. M. Mcdonald, and M. Zayzafoon, "NFATc1: a novel anabolic therapeutic target for osteoporosis," Annals of the New York Academy of Sciences, vol. 1068, no. 1, pp. 564-567, 2006.

[98] J. Stagg and M. J. Smyth, "Extracellular adenosine triphosphate and adenosine in cancer," Oncogene, vol. 29, no. 39, pp. 5346-5358, 2010.

[99] S. Shimegi, "ATP and adenosine act as a mitogen for osteoblast-like cells (MC3T3-E1)," Calcified Tissue International, vol. 58, no. 2, pp. 109-113, 1996. 
[100] B. A. J. Evans, C. Elford, A. Pexa et al., "Human osteoblast precursors produce extracellular adenosine, which modulates their secretion of IL-6 and osteoprotegerin," Journal of Bone and Mineral Research, vol. 21, no. 2, pp. 228-236, 2006.

[101] W. Wei, J. K. Ryu, H. B. Choi, and J. G. McLarnon, "Expression and function of the $\mathrm{P} 2 \mathrm{X} 7$ receptor in rat C6 glioma cells," Cancer Letters, vol. 260, no. 1-2, pp. 79-87, 2008.

[102] G. L. Chen, H. B. Lin, X. W. Wu, R. Y. Li, and X. H. Chen, "The correlation between the level of serum VEGF and bFGF with metastasis and prognosis of osteosarcoma," Xi Bao Yu Fen Zi Mian Yi Xue Za Zhi, vol. 27, no. 12, pp. 1343-1345, 2011.

[103] A. Tzankov, M. Medinger, and N. Fischer, "Vascular endothelial growth factor-related pathways in hemato-lymphoid malignancies," Journal of Oncology, vol. 2010, Article ID 729725, 13 pages, 2010.

[104] R. E. Coleman, "Bone cancer in 2011: prevention and treatment of bone metastases," Nature Reviews Clinical Oncology, vol. 9, no. 2, pp. 76-78, 2012.

[105] R. Hanada, T. Hanada, V. Sigl, D. Schramek, and J. M. Penninger, "RANKL/RANK-beyond bones," Journal of Molecular Medicine, vol. 89, no. 7, pp. 647-656, 2011.

[106] L. M. Hill, M. L. Gavala, L. Y. Lenertz, and P. J. Bertics, "Extracellular ATP may contribute to tissue repair by rapidly stimulating purinergic receptor $\mathrm{X} 7$-dependent vascular endothelial growth factor release from primary human monocytes," Journal of Immunology, vol. 185, no. 5, pp. 30283034, 2010.

[107] M. Barbera-Cremades, A. Baroja-Mazo, A. I. Gomez, F. Machado, V. F. Di, and P. Pelegrin, "P2X7 receptorstimulation causes fever via PGE2 and IL-1beta release," The FASEB Journal, vol. 26, no. 7, pp. 2951-2962, 2012.

[108] J. H. Chong, G. G. Zheng, Y. Y. Ma et al., “The hyposensitive N187D P2X7 mutant promotes malignant progression in nude mice," Journal of Biological Chemistry, vol. 285, no. 46, pp. 36179-36187, 2010.

[109] L. Raffaghello, P. Chiozzi, S. Falzoni, F. Di Virgilio, and V. Pistoia, "The P2X7 receptor sustains the growth of human neuroblastoma cells through a substance P-dependent mechanism," Cancer Research, vol. 66, no. 2, pp. 907-914, 2006.

[110] P. A. Verhoef, M. Estacion, W. Schilling, and G. R. Dubyak, "P2X7 receptor-dependent blebbing and the activation of Rho-effector kinases, caspases, and IL- $1 \beta$ release," Journal of Immunology, vol. 170, no. 11, pp. 5728-5738, 2003.

[111] A. Morelli, P. Chiozzi, A. Chiesa et al., "Extracellular ATP causes ROCK I-dependent Bleb formation in P2X7transfected HEK293 cells," Molecular Biology of the Cell, vol. 14, no. 7, pp. 2655-2664, 2003.

[112] Z. A. Pfeiffer, M. Aga, U. Prabhu, J. J. Watters, D. J. Hall, and P. J. Bertics, "The nucleotide receptor P2X7 mediates actin reorganization and membrane blebbing in RAW 264.7 macrophages via p38 MAP kinase and Rho," Journal of Leukocyte Biology, vol. 75, no. 6, pp. 1173-1182, 2004.

[113] N. Panupinthu, L. Zhao, F. Possmayer, H. Z. Ke, S. M. Sims, and S. J. Dixon, "P2X7 nucleotide receptors mediate blebbing in osteoblasts through a pathway involving lysophosphatidic acid," Journal of Biological Chemistry, vol. 282, no. 5, pp. 3403-3412, 2007.

[114] B. Jelassi, A. Chantme, F. Alcaraz-Pérez et al., "P2X 7 receptor activation enhances SK3 channels- and cystein cathepsindependent cancer cells invasiveness," Oncogene, vol. 30, no. 18, pp. 2108-2122, 2011.
[115] S. Liu, S. Li, and Y. Du, "Polychlorinated biphenyls (PCBs) enhance metastatic properties of breast cancer cells by activating rho-associated kinase (ROCK)," PLoS ONE, vol. 5, no. 6, Article ID e11272, 2010.

[116] N. S. Ruppender, A. R. Merkel, T. J. Martin, G. R. Mundy, J. A. Sterling, and S. A. Guelcher, "Matrix rigidity induces osteolytic gene expression of metastatic breast cancer cells," PLoS ONE, vol. 5, no. 11, Article ID e15451, 2010.

[117] M. Slater, S. Danieletto, M. Pooley, L. C. Teh, A. Gidley-Baird, and J. A. Barden, "Differentiation between cancerous and normal hyperplastic lobules in breast lesions," Breast Cancer Research and Treatment, vol. 83, no. 1, pp. 1-10, 2004.

[118] G. Lopez-Castejon, J. Theaker, P. Pelegrin, A. D. Clifton, M. Braddock, and A. Surprenant, "P2X7 receptor-mediated release of cathepsins from macrophages is a cytokineindependent mechanism potentially involved in joint diseases," Journal of Immunology, vol. 185, no. 4, pp. 2611-2619, 2010.

[119] J. M. Maris, M. D. Hogarty, R. Bagatell, and S. L. Cohn, "Neuroblastoma," The Lancet, vol. 369, no. 9579, pp. 21062120, 2007.

[120] J. M. Maris, "Recent advances in neuroblastoma," The New England Journal of Medicine, vol. 362, no. 23, pp. 2202-2211, 2010.

[121] P. Y. Wu, Y. C. Lin, C. L. Chang et al., "Functional decreases in P2X7 receptors are associated with retinoic acid-induced neuronal differentiation of Neuro-2a neuroblastoma cells," Cellular Signalling, vol. 21, no. 6, pp. 881-891, 2009.

[122] Y. Gutiérrez-Martín, D. Bustillo, R. Gómez-Villafuertes et al., "P2X7 receptors trigger ATP exocytosis and modify secretory vesicle dynamics in neuroblastoma cells," Journal of Biological Chemistry, vol. 286, no. 13, pp. 11370-11381, 2011.

[123] T. Ara and Y. A. DeClerck, "Mechanisms of invasion and metastasis in human neuroblastoma," Cancer and Metastasis Reviews, vol. 25, no. 4, pp. 645-657, 2006.

[124] R. C. Calvert, M. Shabbir, C. S. Thompson, D. P. Mikhailidis, R. J. Morgan, and G. Burnstock, "Immunocytochemical and pharmacological characterisation of P2-purinoceptormediated cell growth and death in PC-3 hormone refractory prostate cancer cells," Anticancer Research, vol. 24, no. 5 A, pp. 2853-2859, 2004.

[125] L. Ravenna, P. Sale, M. Di Vito et al., "Up-regulation of the inflammatory-reparative phenotype in human prostate carcinoma," Prostate, vol. 69, no. 11, pp. 1245-1255, 2009.

[126] Y. Zhang, L. H. Gong, H. Q. Zhang et al., "Extracellular ATP enhances in vitro invasion of prostate cancer cells by activating Rho GTPase and upregulating MMPs expression," Cancer Letters, vol. 293, no. 2, pp. 189-197, 2010.

[127] L. M. Ballou and R. Z. Lin, "Rapamycin and mTOR kinase inhibitors," Journal of Chemical Biology., vol. 1, no. 1-4, pp. 27-36, 2008.

[128] T. Ogawa, M. Tokuda, K. Tomizawa et al., "Osteoblastic differentiation is enhanced by rapamycin in rat osteoblastlike osteosarcoma (ROS 17/2.8) cells," Biochemical and Biophysical Research Communications, vol. 249, no. 1, pp. 226230, 1998.

[129] S. Vemulapalli, A. Mita, Y. Alvarado, K. Sankhala, and M. Mita, "The emerging role of mammalian target of rapamycin inhibitors in the treatment of sarcomas," Targeted Oncology, vol. 6, no. 1, pp. 29-39, 2011.

[130] H. Pang and L. E. Faber, "Estrogen and rapamycin effects on cell cycle progression in T47D breast cancer cells," Breast 
Cancer Research and Treatment, vol. 70, no. 1, pp. 21-26, 2001.

[131] N. Arulkumaran, R. J. Unwin, and F. W. K. Tam, "A potential therapeutic role for $\mathrm{P} 2 \mathrm{X} 7$ receptor (P2X7R) antagonists in the treatment of inflammatory diseases," Expert Opinion on Investigational Drugs, vol. 20, no. 7, pp. 897-915, 2011. 


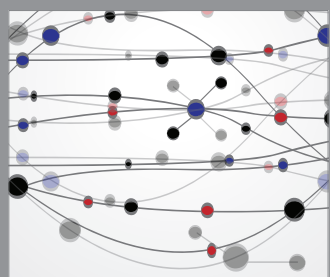

The Scientific World Journal
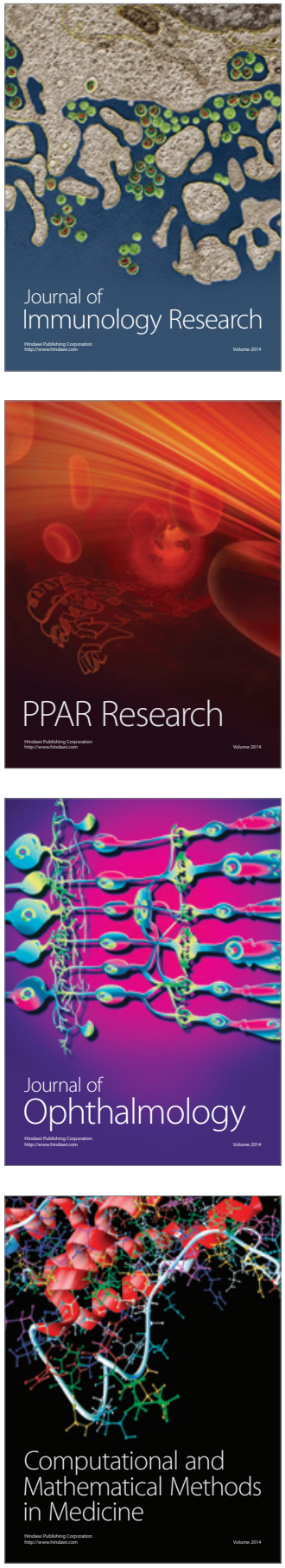

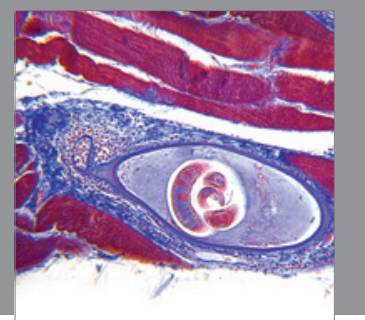

Gastroenterology

Research and Practice
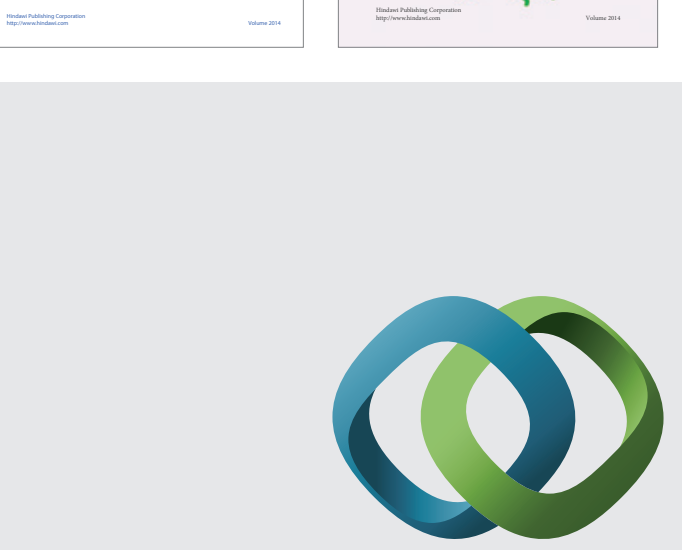

\section{Hindawi}

Submit your manuscripts at

http://www.hindawi.com
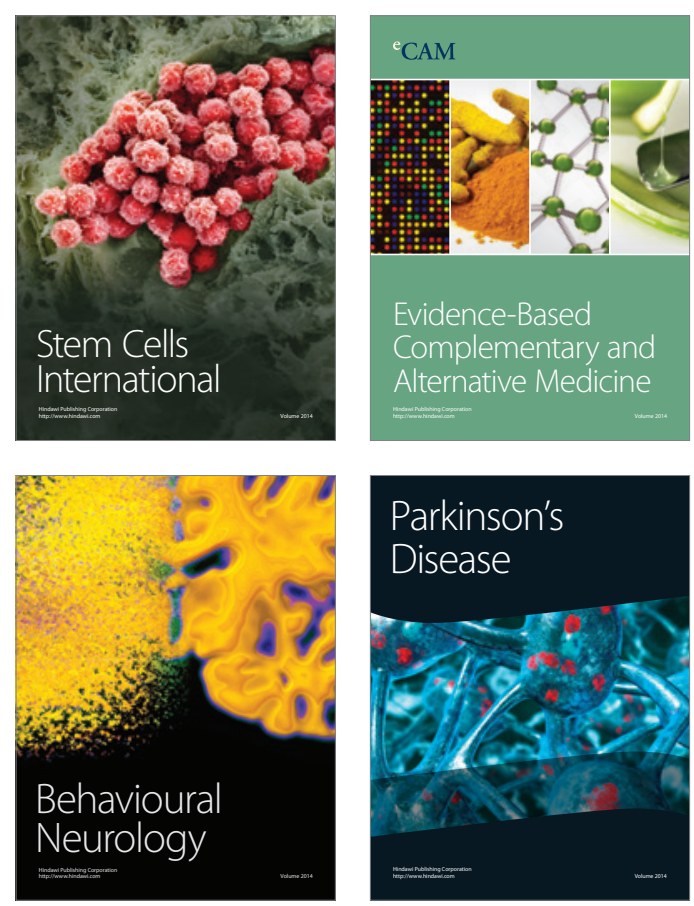

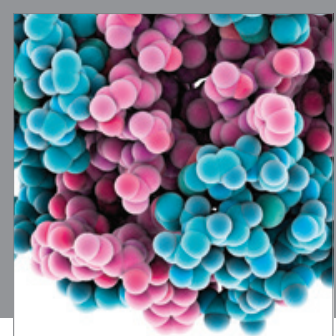

Journal of
Diabetes Research

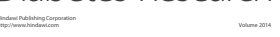

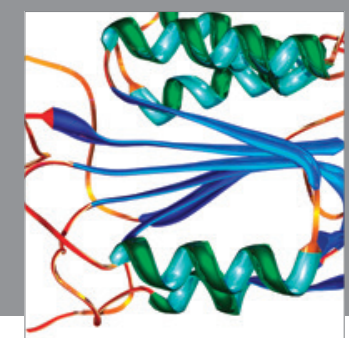

Disease Markers
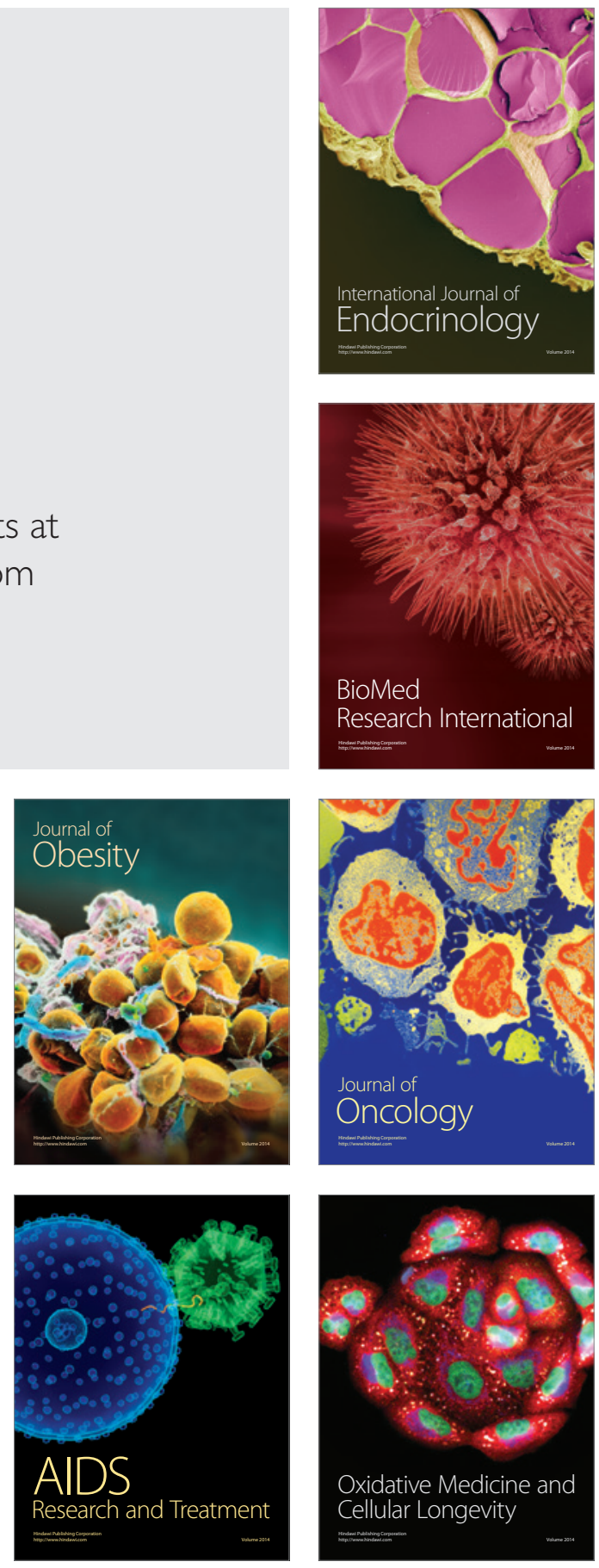